\title{
A Systematic Literature Review on the Potential of Other Tobacco Processing Products (HPTL) as an Alternative Product in Tobacco Harm Reduction
}

\author{
Oktavia Eka Puspita*, Tamara Gusti Ebtavanny, Nurus Sobah
}

Department of Pharmacy, Faculty of Medicine, Brawijaya University, Malang 65145, East Java, Indonesia.

\section{ARTICLE INFO:}

Received: 21 Dec 2020

Accepted: 12 Feb 2021

Published: 28 Feb 2021

\section{Corresponding author *} Oktavia Eka Puspita,

Department of Pharmacy, Faculty of Medicine, Brawijaya University,

Malang 65145, East Java,

Indonesia.

E Mail: oktaviaeka@ub.ac.id

\begin{abstract}
:
Tobacco products other than cigarettes or alternative tobacco products have gained much popularity and perceived as less risk product compared to conventional cigarettes. In Indonesia, the product is known as Hasil Pengolahan Tembakau Lainnya (HPTL) or Other Tobacco Processing Products. Many studies have been done throughout the world and showed that the products have potential in reducing risk of tobacco use. As long as those products have much variety in design neither device nor materials the result may be differ between studies. In this systematic literature review aimed to answers some question concerning issues whether HPTL is less risk compared to conventional cigarettes and does HPTL able in helping smoker to quit smoking. We searched published articles relating to HPTL harm reduction and smoking cessation. The parameters for harm reduction is assessed based on the biomarker of exposure (BoE) levels detected in breath, blood, and urine and also based on the cardiovascular marker measured in participant. Parameters measured for smoking cessation was based on the cigarettes used per day by the participant. Conclusion: for those parameters are HPTL has potential as tobacco harm reduction and help smoker to quit smoking.
\end{abstract}

Keywords: HPTL, alternative tobacco products, tobacco harm reduction, smoking cessation.

\section{INTRODUCTION}

Alternative tobacco products have gained popularity in market especially for smoker. These products have been perceived as a less harmful tobacco product compared to conventional cigarettes [1-3]. In Indonesia, this product is known as Hasil Pengolahan Tembakau Lainnya (HPTL) or Other Tobacco Processing Products. Many studies has been conducted throughout the world concerning good impact of these product in reducing tobacco harm and smoking cessation using various research method and product profiles. Unfortunately, this research has not been conducted in Indonesia. One of this review background is providing evidence based concerning safety and usability of tobacco alternative product. Similar review has been conducted in earlier year but exclusively discuss electronic cigarettes while in this review discuss various tobacco alternative products [4].

There are a lot of tobacco alternative product categories based on raw materials and how they are used by smoker. In many countries, especially in Indonesia, where these products have been marketed, there are still no regulations regarding distribution and use. There is a concern about the unidentified potential hazards of their use, considering that this product always contains nicotine and produces aerosols from its combustion with the accompanying ingredients in the product $[5,6]$. In fact, alternative tobacco products are still in the pros and cons concerning their benefits in reducing the risk of using tobacco-based products and helping smoking cessation. Various type of alternative tobacco products have an impact in chemical content in the aerosol inhaled by the smokers. The design of the device and tobbacco type has a significant influence on the levels of toxic and carcinogenic chemicals in the inhaled smoke. This may lead to different study results [7]. Indonesia is a big market for alternative tobacco products which is why the government must immediately implement regulations. Therefore it is necessary to support scientific evidence related to the safety of these products. Until this review was written there was no clinical research has been published in Indonesia regarding the impact of alternative tobacco products. This review is attempting to provide scientific evidence based on published clinical trial conducted by 
International Journal of Pharma Research and Health Sciences, 2021; 9 (1): 3270-3279

researchers throughout the world. Besides providing scientific evidence for the public and the Indonesian government in particular, it also identifies gaps and suggests further research related to alternative tobacco products. This study will also have an impact on the pharmaceutical and health sectors in terms of the study of formula design and the selection of safer ingredients and determining regulations for their use by the government. In achieving those goals the results of this systematic literature review have to be able in answering the following research questions (RQ):

1) Does the use of alternative tobacco products reduce health risks compared to using cigarettes? (RQ1)

2) Does the use of alternative tobacco products reduce the frequency of cigarettes use (smoking cessation)? (RQ2)

Relevant research results are required to answer the formulation of the question. This systematic literature review is limited to the article with criteria as follows:

1) Inclusion Criteria (IC 1): Articles published in 20152020

2) Inclusion Criteria (IC 2): Research articles using the randomized clinical trial (RCT) and cohort methods

3) Inclusion Criteria (IC 2): Articles are written in English or Indonesian

Articles that do not meet the inclusion criteria and/or articles that contain data regarding HPTL but have the following criteria will not be used to answer the research questions. However, it is possible to use them as supporting data only. The article exclusion criteria are as follows:

1) Exclusion Criteria (EC 1): Articles before 2015

2) Exclusion Criteria (EC 2): Article in the form of Literature review or Systematic Literature Review

3) Exclusion Criteria (EC3): Articles are written other than using English and Indonesian

4) Exclusion Criteria (EC 4): Research using animal objects

5) Exclusion Criteria (EC 5): Research using in vitro methods

\section{OTHER TOBACCO PROCESSING PRODUCTS (HPTL)}

HPTL is defined in Indonesian as Hasil Pengolahan Produk Lainnya, or in English is translated as Other Tobacco Processing Products or alternative tobacco product. There are many variety alternative tobacco product based on its raw material and the production of inhaled aerosol. In accordance with technological developments alternative tobacco products including tobacco extracts and essences, molasses tobacco, snuff tobacco, or chewing tobacco. The term of HPTL for the purposes of searching for scientific publication articles globally was not found. Therefore other terms that had similar meanings to the HPTL product category were used as stated in the article search keyword combination. Electronic cigarettes are one of the most popular alternative tobacco product types. The products consist of soluble nicotine in glycerine and/or propylene glycol with electric heater to produce aerosol to be inhaled by smoker.

\section{METHOD}

This study was conducted in five-step adopted from method used by Rowley and Slack in conducting a Systematic Literature Review (SLR). General steps conducted in this review is depicted in (Figure 1)[8]. The five steps are as follows: (1) formulating research question and identifying keywords; (2) searching in digital database using determined keywords; (3) articles selection based on inclusion and exclusion criteria; (4) articles selection based on full text; and (5) data extraction from selected article and reporting.

3.1 Formulating Research Question and Identifying Keywords

Search for articles begins by determining the keyword combination that matches the research question formulated earlier. These keywords are used to scan documents on a digital database. The keyword combination used was "ENDS” OR "ENNDS" OR"electronic cigarette"OR "vape" OR "Heated Tobacco Product" OR "nicotine pouch"OR "snus" OR "heat-not-burn"OR"smoking cessation"OR"tobacco harm reduction"OR"cigarettes". The digital databases used in this research were Google Scholar, Crossref, and Scopus. From the search results, 1000 articles were obtained from Google Scholar, 200 articles from Scopus, and 200 articles from Crossref. The total number of articles is 1400 titles.

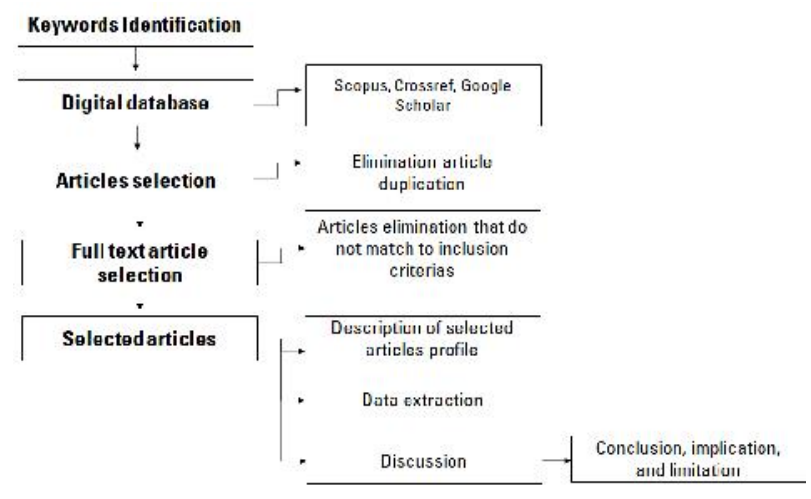

Fig 1. SLR Process (adopted from Rowley and Slack, 2004)

The next step is to sort the articles obtained from the three digital databases based on their suitability with inclusion and exclusion criteria. This sorting is the initial stage carried out individually by the researcher on the abstract of each article. In this step, the elimination of duplicated articles is also carried out. The number of duplicated articles in the 1400 articles is 128 titles. The number of articles that met the inclusion criteria was 34 articles.

\subsection{Selected Article Profiles}

Meta-information which includes title, author name, abstract, journal title, publisher, year published, number of citations, and journal impact factor for the 34 selected articles is extracted and saved in .csv format. Figure 2 shows the trend in the publication of articles over the years. The 
International Journal of Pharma Research and Health Sciences, 2021; 9 (1): 3270-3279

methods used in those studies varied between Randomized

Control Trial (RCT) and Cohort.

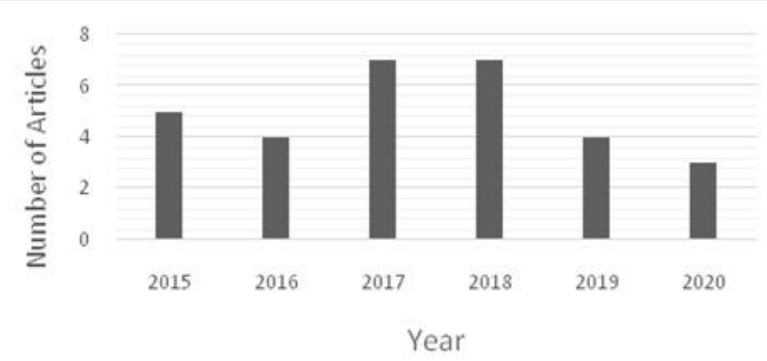

Fig 2: Trend of the Number of Articles Each Year in the 2015-2020 Range

Figure 3 illustrates the contribution of each country to the published study in alternative tobacco products. The determination of the country is based on where the author is affiliated. The origin-country of the article does not fully reflect the origin of the research object (human respondents may varied such as those who happen to be domiciled in the country where the research was carried out). This figure shows that most of the research came from the three main countries. The highest number of research was from USA followed by Switzerland and Italy. All the articles were published in journals that have Impact Factors. This shows the significance of the importance of research and the quality of the journal in contributing to the field being researched so that it can be called a valid journal. Apart from the Impact Factor, the journals' quality can also be seen from the citation as shown in Table 1.

Citation analysis is carried out to determine the importance of an article and the level of relevance between the articles. Table 1 shows the ranking of influential articles that contributed to providing research facts in the HPTL domain. The number of citations and citations per year, that is, the average number of citations (calculated by the number of citations received by an article divided by the number of years since publication) were both used as a measure to determine the most influential articles. Citations per year were also measured because some articles were likely to receive more citations for being published earlier. Whereas, the zero citation is likely because it is a newly published journal.

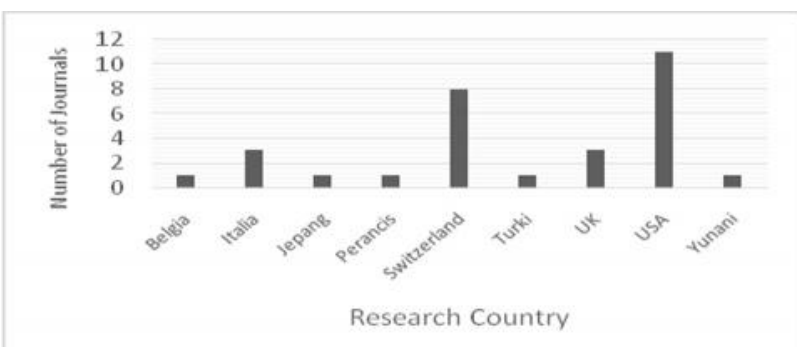

Fig 4: Country Profile of Research Site
Table 1: Main articles based on the number of citations

\begin{tabular}{|c|c|c|c|c|c|c|c|}
\hline Rank & $\begin{array}{l}\text { Author } \\
\text { (Year) }\end{array}$ & \begin{tabular}{|c|} 
Citatio \\
ns
\end{tabular} & $\begin{array}{c}\text { Citatio } \\
\text { ns/Yea } \\
\mathbf{r}\end{array}$ & $\begin{array}{c}\text { Ran } \\
\mathbf{k}\end{array}$ & $\begin{array}{l}\text { Author } \\
\text { (Year) }\end{array}$ & $\begin{array}{c}\text { Citati } \\
\text { ons }\end{array}$ & $\begin{array}{c}\text { Citations/ } \\
\text { Year }\end{array}$ \\
\hline 1 & $\begin{array}{l}\text { McConnell } \\
(2017)[29]\end{array}$ & 152 & 50.67 & 18 & $\begin{array}{c}\text { Lüdicke } \\
\text { (2016) [24] }\end{array}$ & 19 & 4.75 \\
\hline 2 & $\begin{array}{c}\text { Hecht (2015) } \\
{[19]}\end{array}$ & 121 & 24.20 & 19 & $\begin{array}{c}\text { Brossard } \\
(2017)[12]\end{array}$ & 19 & 6.33 \\
\hline 3 & \begin{tabular}{|c|} 
Yan (2015) \\
{$[36]$} \\
\end{tabular} & 86 & 17.20 & 20 & $\begin{array}{c}\text { Adriaens } \\
(2018) \text { [38] }\end{array}$ & 17 & 8.50 \\
\hline 4 & $\begin{array}{c}\text { Manzoli } \\
(2017)[27]\end{array}$ & 73 & 24.33 & 21 & $\begin{array}{c}\text { Kerr (2019) } \\
{[21]}\end{array}$ & 17 & 17.00 \\
\hline 5 & $\begin{array}{c}\text { Manzoli } \\
\text { (2015) [28] }\end{array}$ & 58 & 11.60 & 22 & $\begin{array}{c}\text { Stein (2015) } \\
{[35]}\end{array}$ & 14 & 2.80 \\
\hline 6 & $\begin{array}{c}\text { Haziza } \\
(2016)[18]\end{array}$ & 50 & 12.50 & 23 & $\begin{array}{c}\text { Meier (2017) } \\
{[30]}\end{array}$ & 14 & 4.67 \\
\hline 7 & $\begin{array}{c}\text { Lüdicke } \\
\text { (2018) [26] }\end{array}$ & 45 & 22.50 & 24 & $\begin{array}{c}\text { Miura (2015) } \\
{[31]}\end{array}$ & 12 & 2.40 \\
\hline 8 & $\begin{array}{c}\text { O'Connell } \\
(2016) \text { [37] }\end{array}$ & 43 & 10.75 & 25 & $\begin{array}{c}\text { Lüdicke } \\
\text { (2019) [25] }\end{array}$ & 12 & 12.00 \\
\hline 9 & $\begin{array}{c}\text { Glantz } \\
(2018)[16]\end{array}$ & 38 & 19.00 & 26 & $\begin{array}{c}\text { Gale (2017) } \\
{[15]}\end{array}$ & 10 & 3.33 \\
\hline 10 & $\begin{array}{l}\text { Ikonomidis } \\
\text { (2018) [20] }\end{array}$ & 35 & 17.50 & 27 & $\begin{array}{l}\text { Hatsukami } \\
(2020) \text { [39] }\end{array}$ & 3 & 3.00 \\
\hline 11 & $\begin{array}{c}\text { Nocella } \\
\text { (2018) [32] }\end{array}$ & 34 & 17.00 & 28 & $\begin{array}{c}\text { Gale (2020) } \\
{[14]}\end{array}$ & 0 & 0.00 \\
\hline 12 & $\begin{array}{c}\text { Lüdicke } \\
\text { (2017) [23] }\end{array}$ & 31 & 10.33 & 29 & $\begin{array}{c}\text { Bosilkovska } \\
(2020)[11]\end{array}$ & 0 & 0.00 \\
\hline 13 & $\begin{array}{l}\text { Biondi-Zocca } \\
\text { i (2019) [10] }\end{array}$ & 30 & 30.00 & & & & \\
\hline 14 & $\begin{array}{c}\text { Rigotti } \\
\text { (2018) [34] }\end{array}$ & 28 & 14.00 & & & & \\
\hline 15 & $\begin{array}{l}\text { Lorkiewicz } \\
(2019)[22]\end{array}$ & 22 & 22.00 & & & & \\
\hline 16 & $\begin{array}{c}\text { Göney } \\
\text { (2016) [17] }\end{array}$ & 21 & 5.25 & & & & \\
\hline 17 & $\begin{array}{l}\text { Pasquereau } \\
\text { (2017) [33] }\end{array}$ & 20 & 6.67 & & & & \\
\hline
\end{tabular}

\section{FINDINGS FROM THE SYSTEMATIC LITERATURE REVIEW}

A complete review summary of 30 selected articles is presented in Table 2. The selected articles were classified into two main themes that are (1) the effect of HPTL on health (RQ1) and (2) the effect of HPTL on smoking cessation (RQ2). The theme of classification was based on research question that will be answered in this research. From the 30 of selected articles, the types of HPTL products being studied can also be identified. Table 3 shows a summary of the HPTL product types and descriptions.

4.1 Profile of HPTL Products Used in Selected Articles

Table 3 identifies the various variations of alternative tobacco products used in the selected articles. The impact of the alternative tobacco products were compared to conventional cigarette which was termed as cigarette. This cigarette refers to cigarettes originated from tobacco leaves as its raw material and used by burning the cigarette and inhaling the aerosols produced. Aerosol refers to the smoke from burning cigarettes. The alternative tobacco products used were non-combustion inhaler type of tobacco product (NCIT), a carbon-heated tobacco product (CHTP), Tobacco Heating System (THS) 2.2, Tobacco Heating Product, 
International Journal of Pharma Research and Health Sciences, 2021; 9 (1): 3270-3279

tobacco Heating System (THS) 2.1, menthol Tobacco Heating System. 2.2 (mTHS), heat-not-burn cigarettes (HNBC), electronic cigarette (blu e-cigs), electronic cigarette: blu ${ }^{\mathrm{TM}}$ e-cigarette, nicotine-free e-cig fluid, e-cig fluid with nicotine, Electronic cigarettes: tobacco-flavored E-cigarette, IQOS (menthol), electronic vaping cigarettes (EVC), Grizzly Premium Straight ST, NJOY King ecigarette, NJOY King Menthol, Carbon-Heated Tobacco Products (CHTP). All types of products can be categorized based on their raw materials as follows: (1) fine tobacco powder formed into sticks (tobacco stick); and (2) a liquid containing nicotine dissolved in the main solvent of glycerin and propylene glycol. Another form of the product is a kind of candy containing nicotine which is consumed orally (Nicotine Gum/Lozenges). For all types of HPTL products (except orally), aerosols are generated by heating, not combustion. Each product has a different design and heat source specification. Overall, from all articles previously obtained (selected and unselected), the types of products included in the researches publication were e-cigarettes (1145 articles), tobacco heating system (THS) (172 articles), nicotine gum (18 articles), and lozenges (76 articles). The electronic cigarette is the most dominant type. This can be an indication that the trend of electronic cigarette products is high.

\subsection{Effect of HPTL on Health}

Explanation of the first question (RQ1) is reviewed in this sub-chapter. The complete resume of each article is available in supplement 1. The first research question is "Does the use of alternative tobacco products reduce health risks compared to using cigarettes?". Research conducted by Miura concluded that participants who switched from cigarettes to HPTL Non-Combustion Inhaler Type (NCIT) showed a significant reduction in all biomarkers of exposure $(\mathrm{BoE})$. Participants who used NCIT had similar biomarker profiles to participants who were nonsmokers (non-smoker, NS), and always lower than cigarette users. These results can be used as an indication of a reduced risk of the dangers of smoking when using NCIT [31].

Biomarker of Exposure is a biological marker parameter produced by the body indicating that a person has been exposed to constituents resulting from burning or heating cigarettes. BoE that appears in the body is caused by exposure to cigarettes in the form of chemical components in the smoke of cigarettes inhaled by humans. The biomarker is the same compound contained in the smoke of cigarettes and the metabolic products after the smoke is inhaled by the user. These compounds are nicotine, carbon monoxide (CO), nicotine, and 4-(methylnitrosamino)-1- (3-pyridyl) -1butanone (NNK), acrolein, crotonaldehyde, 1, 3-butadiene, benzene, pyrene, 4-ABP, hydrogen cyanide ( $\mathrm{HCN})$, and mutagens. These compounds are toxic and carcinogenic. Therefore, its level of presence in the body can be used as a risk parameter that leads to the adverse effects of using cigarettes [31].
Another research evaluating the presence of $\mathrm{BoE}$ was also conducted by Hecht [12]. The result showed that the level of biomarkers 1-HOP, total NNAL, 3-HPMA, 2-HPMA, HMPMA, and SPMA were significantly lower in the urine of e-cigarette users compared to smokers. Similar study by Lüdicke measured $\mathrm{BoE}$ in urine excretion, showing that the mutagenic content decreased sharply on day-5 in HPTL users of the carbon-heated tobacco product (CHTP) type compared to the original level (before switching to CHTP) in the same participants[23, 24]. Whereas for cigarette users, there is no change in the biomarker profile. This indicates a decrease in the level of hazardous exposure in smokers switching from cigarettes to CHTP (under controlled conditions). A similar research model was also conducted by O'Connell [37], who reported the results of his research related to the content of biomarkers in the bodies of participants who used HPTL compared to cigarettes. Overall, smokers who completely or partially replaced cigarettes with e-cigarettes (dual-user) for five days experienced a decrease in biomarkers. Gale [15] reported that on day-5 after switching from cigarettes to HPTL type glo $^{\mathrm{TM}}$ or iQOS, urinary BoE and carbon monoxide levels in exhaled breath (eCO) were significantly reduced by an average of between $20.9 \%$ and $92.1 \%$ compared to baseline (before switching to HPTL products). Of the three researches, it shows that there is a decrease in BoE in smokers who switch from cigarettes to HPTL. The types of HPTL used by each researcher are as described in Table 3.

Haziza [18] reported that the biomarkers of exposure in the Tobacco Heating System (THS) 2.2 HPTL users were significantly reduced compared to the cigaretteuser group. The biomarkers are COHb, S-PMA, MHBMA, and 3-HPMA which are the result of exposure to cigarette smoke in the form of carbon monoxide, benzene, 1,3 butadiene, and acrolein. Even so, the research conducted by Göney reported that nicotine levels in the urine of participants have no statistically significant differences between e-cigarette users and smokers. Göneyin his research, compared the amount of cotinine (the main metabolite of nicotine) in the urine of e-cigarette users, smokers, and passive smokers. Göney did not evaluate BoE levels in the participants' bodies [17].

McConnell [29] also conducted a 12-month cohort survey of participants who met the criteria. Participants were asked to voluntarily report the presence or absence of symptoms of chronic bronchitis (chronic cough, sputum, or bronchitis) when using alternative tobacco products compared to cigarettes. In this research, McConnell did not interverethe participants but instead collected data according to the questionnaires filled out by participants. The result showed that the risk of bronchitis symptoms in participants who had previously used e-cigarettes remained high. This means that adjusting the habit of smoking using e-cigarettes does not reduce the risk of bronchitis. Meanwhile, adolescents who use e-cigarettes experience an increase in 
International Journal of Pharma Research and Health Sciences, 2021; 9 (1): 3270-3279

symptoms of chronic bronchitis. Further investigations are needed to determine the long-term effects of e-cigarettes on respiratory health [29].

Lüdicke [23] reported that $\mathrm{BoE}$ against tobacco smoke toxicity provided an indication that product risk assessment was significantly reduced with THS use compared to the CC (cigarette) group. THS 2.1 is a promising alternative to $\mathrm{CC}$. Regardless of the possible adaptation of use through ingestion or steaming behavior, exposure to hazardous smoke constituents was markedly reduced with the new heated tobacco platform. Markers of exposure to hazardous and potentially hazardous smoke constituents were derived by THS 2.1. Another study by Lüdicke $[25,26]$ reported that after 5 days of using mTHS products (Table 3) the concentrations of $\mathrm{BoE}$ of carboxyhemoglobin, 3-hydroxypropylmercapturic acid, monohydroxybutenyl mercapturic acid, and Sphenylmercapturic acid respectively were 55\%, 49\%, 87\%, and $89 \%$ lower in the use of mTHS compared to the menthol cigarette (mCC). These decreases remained consistent through day-90 and were similar to results in the nonsmoking (SA) group. Switching from CC to mTHS was associated with an increase in clinically relevant risk markers related to the mechanical pathways involved in the smoking-related disease. In this research, it was also reported that the switch from cigarettes to mTHS for 5 days resulted in changes in oxidative stress biomarkers, platelet activity, endothelial function, high-density lipoprotein cholesterol (DHL), and lung function similar to participants in the non-smoking group (SA). The results suggest that switching to mTHS has the potential to reduce the detrimental health effects of cigarettes. Similar research regarding the observation of the BoE profile was also carried out by Gale [14] who reported that in the smoking group, the baseline and day-90 $\mathrm{BoE}$ values were stable, while the $\mathrm{BoE}$ values in glo-THP users decreased significantly compared to cigarette users.

Research showing different results conducted by Glantz [16] reported no significant difference in results in 23 out of $24 \mathrm{BoE}$ tested on IQOS ${ }^{\mathrm{TM}}$ users with cigarettes in America. The test was also carried out on other research participants in Japan and the results showed no significant difference in 10 out of 13 harmful biomarkers tested between IQOS ${ }^{\mathrm{TM}}$ users with cigarettes. The results of this research indicate that $\mathrm{IQOS}^{\mathrm{TM}}$ is no safer than cigarettes. However, based on the results of other researches, BoE HPTL is not higher than cigarettes. This is also shown by Bosilkovska[11] who reported that after 5 days of use, the BoE in the use of Carbon-Heated Tobacco Products (CHTP) was $40 \%-95 \%$ lower than cigarettes. At baseline (day-5), nicotine exposure in CHTP was higher than cigarettes, but at the end of the research period (day-90), nicotine exposure in both groups were almost the same. Switching cigarettes to CHTP significantly reduces exposure to harmful and potentially harmful constituents (HPHC).
Another parameter of the impact of HPTL was researched by Nocella [32] who reported the acute effect of cigarette use compared to e-cigarettes in smoker and nonsmoker participants. The parameters for the acute effect were the levels of sCD40L and sP-selectin in the blood before and after treatment compared to the initial levels. sCD40L and sP-selectin are biomarkers of the development or risk of vascular disease. In smokers, there were no significant increase in levels of sCD40L and sP-selectin, but a significant increase in the occurrence of platelet aggregation. Overall, both and e-cigarettes have an acute impact on platelet activation. Ikonomidis[13] reported that cigarettes and e-cigarettes both have a negative effect on blood vessel elasticity and levels of oxidative stress. However, the increase in blood vessel stiffness in nicotinefree e-cigarette users was lower than in cigarettes. Replacing cigarettes with e-cigarettes containing nicotine can also reduce systolic blood pressure and oxidative stress levels within 1 month. The results of this research recommend the use of e-cigarettes as a substitute for cigarettes in a medically supervised smoking cessation program.

Kerr [21] reported that the pulse rate increased significantly after the use of e-cigarettes and tobacco cigarettes. Meanwhile, the level of blood pressure and augmentation index tends to remain constant. The total value of microparticles, especially platelet microparticles (PMPs) and endothelial microparticles (EMPs) was significantly increased in tobacco cigarette users, whereas in e-cigarette users, the values increased significantly only in the PMPs group. E-cigarettes and tobacco both have a negative impact on blood vessel function and respiratory function. This tends to be in contrast to research conducted by Yan [36] who reported that heart rate, systolic and diastolic blood pressure increased significantly after using Marlboro ${ }^{\circledR}$ brand cigarettes, but these increases were reduced after switching to blu e-cigs (product description is in Table 3). The use of blu e-cigs had no impact on carbon monoxide (CO) levels in exhaled breath, whereas Marlboro ${ }^{\circledR}$ cigarettes significantly increased exhaled $\mathrm{CO}$ more than 8 times above baseline levels. The conclusion of this research is that blu e-cigs can be a less dangerous alternative for tobacco users. Yan [36] study results supported by the research conducted by BiondiZoccai [10] on Heat-not-burn cigarettes (HNBC) and electronic vaping cigarettes (EVC). Both types of HPTL have a lower impact on flow mediated dilation (FMD) response than tobacco combustion cigarettes (cigarettes). FMD is a parameter measurement method for assessing endothelial function systemically, namely, to describe markers associated with the presence of risk factors for cardiovascular disease. A lower FMD response indicates a low impact, meaning that the risk factor for cardiovascular disease is also low. Other parameters measured in the Biondi Zoccai [10] research included the participants' blood pressure, which showed that the effect of HNBC on blood pressure was lower than EVC. This research is preliminary 
International Journal of Pharma Research and Health Sciences, 2021; 9 (1): 3270-3279

in nature and requires confirmation of other similar researches. Of the three types of products tested in the research, HNBC gave better results than EVC and cigarettes, but this should still require further clinical studies.

\subsection{The Effect of HPTL on Smoking Cessation}

The second research question is "Does the use of alternative tobacco products reduce the frequency of cigarettes use (smoking cessation)?" is reviewed in this subchapter. Complete resume of each article is available in supplement 2. The safety of using e-cigarettes is still a matter of debate. Some experts suspect that e-cigarettes can reduce smokers' motivation to quit smoking and trigger new smokers to emerge. On the other hand, the opinion of other experts claims that e-cigarettes can be an attractive and inexpensive strategy to stop or reduce the frequency of using cigarettes so that they are expected to reduce the health risks arising from cigarettes [28]. However, there is no research evidence to support these claims. Of the 34 articles that were included in the inclusion criteria, 9 of them discussed the effect of replacing cigarettes with HPTL on smoking cessation of cigarettes listed in table 4.2. The types of HPTL used as a substitute for cigarettes in this research included ecigarettes, THS 2.2, IQOS ${ }^{\mathrm{TM}}$, nicotine gum, and lozenges. Based on this research, $55.5 \%$ of the research results stated that the use of HPTL products was significantly able to reduce the frequency of using cigarettes. Although there is no research that states that the use of HPTL is able to stop the use of cigarettes, the reduction in the frequency of use has a positive impact on reducing health risks [28, 35].

The incidence of side effects associated with the use of tobacco cigarettes is Acute Myocardial Infarction (AMI), Chronic Obstructive Pulmonary Disease (COPD), pneumonia, and angina [28]. The reduction in health risks associated with the reduction in smoking frequency was also indicated by lowering levels of biomarkers such as $\mathrm{CoHb}$ (Carboxyhemoglobin). $\mathrm{CoHb}$ is a biomarker whose levels increase due to exposure to carbon monoxide [18].

The reduction in smoking frequency is viewed from two aspects, namely based on standardized questionnaires such as the Glover-Nilsson Smoking Behavioral Questionnaire, Urge-to-smoke symptoms (QSU brief), Modified Cigarette Evaluation Questionnaire, Minnesota Nicotine Withdrawal Scale, Modified Cigarettes Evaluation Questionnaire; measurement of levels of nicotine exposure; and carbon monoxide in the exhaled air by the participants (exhaled carbon monoxide/e-CO) [38, 12, 18, 30].

Dual-user smokers (users of e-cigarettes and cigarettes) are more difficult to quit or reduce smoking frequency compared to e-cigarette users alone [28]. Based on research conducted by Brossard [12] the pharmacokinetic profiles of $\mathrm{C}_{\max }$ (maximum concentration) and AUC (Area Under Curve) of nicotine in the THS were similar to cigarettes with a concentration range of $88 \%-104 \%$ for $\mathrm{C}_{\max }$ and $96 \%$ - $98 \%$ for AUC. The total score of smoking cravings as measured using the USQ Brief questionnaire on THS is also similar to cigarettes. eCO levels in users of THS, ecigarettes, nicotine gum and lozenges were lower than cigarettes[38, 19]. This shows that the use of THS and ecigarettes can be an alternative to cigarettes.

The limitations of this research are the small sample size and short research time. So that the effectiveness of the impact of using HPTL in reducing the frequency of cigarette use on reducing health risks cannot be clearly assessed. Measurement of biomarker levels in the research was not associated with a potential risk of developing a disease. Therefore, it is necessary to carry out further research by increasing the number of samples and the length of time of the research and linking the decrease in the frequency of cigarette use to a decrease in health risks.

\section{GAP AND SUGGESTIONS FOR FURTHER RESEARCH}

5.1 Gap against Tobacco Harm Reduction and Smoking Cessation Aspects

The results and conclusions in all these researches are preliminary data that need follow-up research. Study in selected articles were mostly observed BoE levels without biomarkers associated with the presence of cardiovascular disease risk factors so that the data obtained were less comprehensive. Apart from the varied products, the limitations of the research were the duration and number of samples (research objects). It needs a longer duration and a larger sample size. There are also less of research articles that discuss the parameters of "harm reduction" and "smoking cessation" on a continuous basis.

5.3 Suggestions for Further Research

Each country need to conduct clinical trial concerning specified products marketed in the country. This is in relation to difference in raw material dan product design that may lead to differ study results. The research should consider many parameters to be measured in order achieving comprehensive analysis.

5.4 Suggestions for Regulation of HPTL Products

In determining whether HPTL is considered as "safe," it is necessary to consider the following aspects: type and composition of raw material, device and packaging design, product information, product labeling, warnings, and instructions for use.

\section{CONCLUSION}

Measurement of a biomarker of exposure (BoE) levels showed a decrease in the use of various types of tobacco alternative products or HPTL. This result indicates that HPTL has potential in reducing health risk of using tobacco. HPTL also helps smoker in reducing frequency and amount of conventional cigarettes used per day. But all of these study conducted by researchers suggested further clinical trial. 
International Journal of Pharma Research and Health Sciences, 2021; 9 (1): 3270-3279

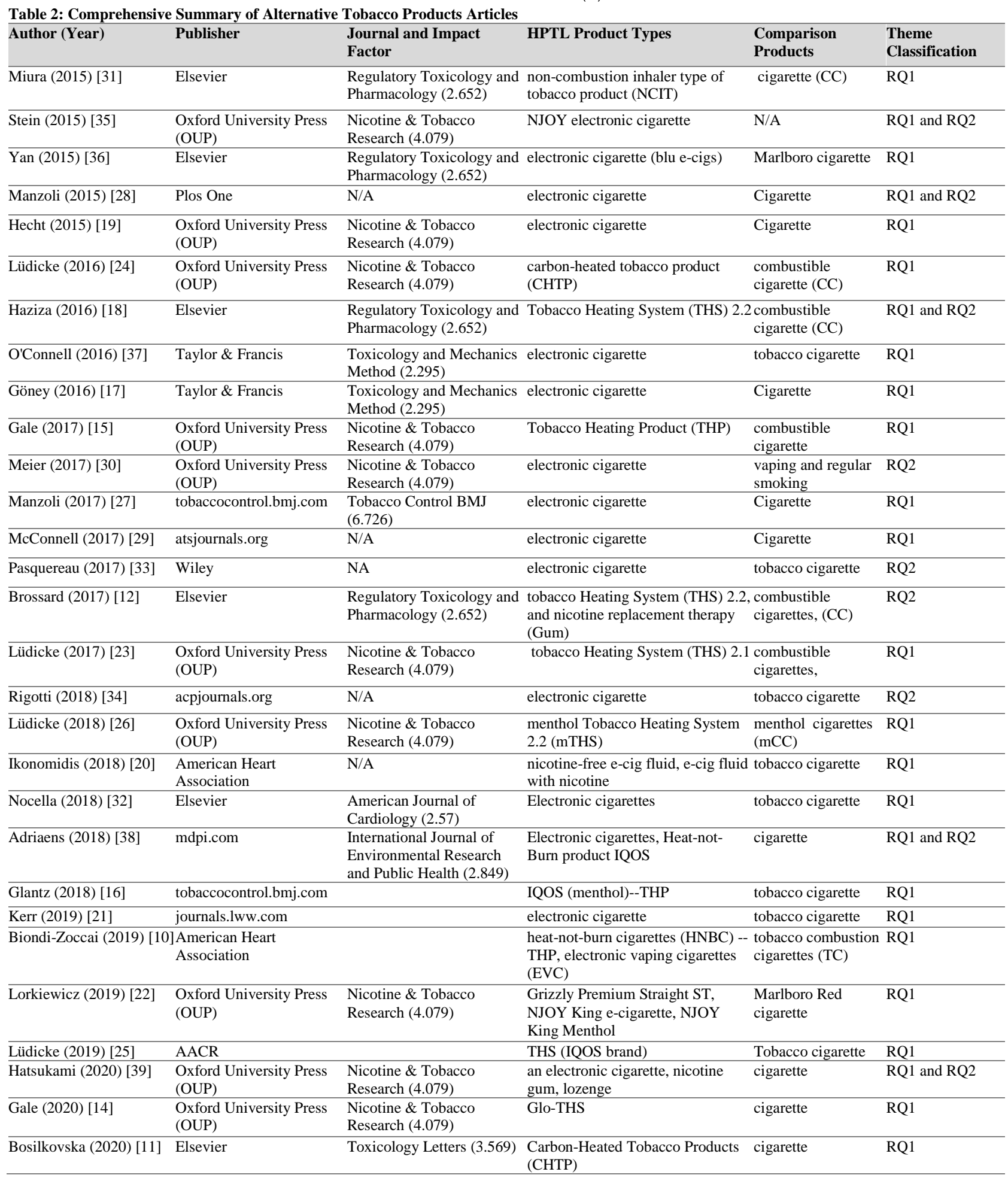

Table 3: Types and descriptions of HPTL products used in selected literature

\begin{tabular}{|c|c|c|}
\hline Author (Year) & Product & Description \\
\hline Miura (2015)[31] & $\begin{array}{l}\text { non-combustion } \\
\text { inhaler type of tobacco } \\
\text { product (NCIT) }\end{array}$ & $\begin{array}{l}\text { Non-combustion Inhaler Type of Tobacco Product (NCIT) is a smokeless tobacco product. The volatile } \\
\text { substances from the tobacco are coming from the cartridge instead of burning or heating the tobacco.The } \\
\text { substances come out due to the presence of airflow resulting from the aspiration (inhalation) of the user. Other } \\
\text { ingredients other than tobacco in NCIT products are water, flavorings, potassium carbonate, and propylene } \\
\text { glycol. }\end{array}$ \\
\hline Yan (2015)[36] & $\begin{array}{l}\text { electronic cigarette } \\
\text { (blu e-cigs) }\end{array}$ & $\begin{array}{l}\text { There are two types of blu e-cigs used in this research, namely Product D and E which contain } 16 \mathrm{mg} / \mathrm{mL}(1.6 \%) \\
\text { nicotine (USP grade): } \\
\text { - Product D: Classic Tobacco e-cigarette is packaged in a rechargeable cartomizer containing } 1.6 \% \text { nicotine, } \\
75 \% \text { glycerin vehicle. In this research, it is referred to as Product D Classic e-cig (1.6\% Nic in Gly). } \\
\text { - Product E: Classic Tobacco e-cigarette is packaged in a rechargeable cartomizer containing } 1.6 \% \text { nicotine, } 50 \%\end{array}$ \\
\hline
\end{tabular}


International Journal of Pharma Research and Health Sciences, 2021; 9 (1): 3270-3279

\begin{tabular}{|c|c|c|}
\hline Author (Year) & Product & Description \\
\hline & & $\begin{array}{l}\text { glycerin / 20\% propylene glycol vehicle. In this research, it is referred to as Product E Classic e-cig (1.6\% Nic } \\
\text { in Gly / PG). }\end{array}$ \\
\hline Lüdicke (2016)[24] & $\begin{array}{l}\text { carbon-heated tobacco } \\
\text { product (CHTP) }\end{array}$ & $\begin{array}{l}\text { In this research, CHTP is a product of an HPTL prototype coded MD2-E7. This prototype consists of a carbon } \\
\text { heat source, a paper-wrapped tobacco stopper, an empty tube (for the transfer of heated aerosols), and a filter (an } \\
\text { aluminum foil strip that attaches a carbon heat source to the tobacco plug/stopper). }\end{array}$ \\
\hline Haziza (2016)[18] & $\begin{array}{l}\text { Tobacco Heating } \\
\text { System (THS) } 2.2\end{array}$ & $\begin{array}{l}\text { Made form tobacco leaves which heated by electrically heating element. The processed tobacco leaves is formed } \\
\text { into stick similar to conventional cigarettes. The tobacco sticks are designed to produce about } 14 \text { puffs. THS } 2.2 \\
\text { contains } 0.5 \mathrm{mg} \text { of nicotine and } 56.4 \mathrm{mg} \text { of glycerin/stick. }\end{array}$ \\
\hline $\begin{array}{l}O^{\prime} \text { Connell (2016)[37 } \\
\end{array}$ & $\begin{array}{l}\text { ]electronic cigarette: } \\
\text { blu }{ }^{\mathrm{TM}} \text { e-cigarette }\end{array}$ & $\begin{array}{l}\text { blu }{ }^{\mathrm{TM}} \text { e-cigarette produced by Fontem Ventures B.V., The Netherlands. The product variations used in this } \\
\text { research are rechargeable tobacco flavor, rechargeable cherry flavor and disposable cherry flavor. }\end{array}$ \\
\hline Gale (2017)[15] & $\begin{array}{l}\text { Tobacco Heating } \\
\text { Product }\end{array}$ & $\begin{array}{l}\text { glo }{ }^{\mathrm{TM}} \text { tobacco heating product (THP1.0) is tobacco heated using electronic components to a temperature of } 240 \\
{ }^{\circ} \mathrm{C} \text {. This heating temperature is lower, resulting in the emission of toxic compounds in lower level than that of } \\
\text { cigarettes. }\end{array}$ \\
\hline Lüdicke (2017)[23] & $\begin{array}{l}\text { tobacco Heating } \\
\text { System (THS) } 2.1\end{array}$ & $\begin{array}{l}\text { Tobacco Heating System (THS) version } 2.1 \text { is an advanced version of the previous prototype product, THS } 1.0 \text {. } \\
\text { This product uses heated tobacco sticks and is only able to produce } 8 \text { puss per stick. The maximum temperature } \\
\text { that can be produced is around } 550^{\circ} \mathrm{C} \text {. }\end{array}$ \\
\hline Lüdicke (2018)[26] & $\begin{array}{l}\text { menthol Tobacco } \\
\text { Heating System } 2.2 \\
\text { (mTHS) }\end{array}$ & $\begin{array}{l}\text { mTHS contains } 2.62 \mathrm{mg} \text { methol, } 1.21 \mathrm{mg} \text { nicotine, and } 3.94 \mathrm{mg} \text { glycerin per stick. The maximum heating } \\
\text { temperature is } 350^{\circ} \mathrm{C} \text {. The aerosols inhaled by the smokersare produced by heating (not burning) the glycerin } \\
\text { component. }\end{array}$ \\
\hline $\begin{array}{l}\text { Ikonomidis } \\
(2018)[20]\end{array}$ & $\begin{array}{l}\text { nicotine-free e-cig } \\
\text { fluid, e-cig fluid with } \\
\text { nicotine }\end{array}$ & $\begin{array}{l}\text { nicotine-free e-cig fluid (NOBACCO eGo Epsilon BDC 1100, eGo battery, } 1100 \mathrm{mAh} \text {, operating at } 3.9 \mathrm{~V} \\
\text { nicotine } 1.2 \% \\
\text { nicotine concentration of } 12 \mathrm{mg} / \mathrm{mL} \text { (propylene glycol } 74.3 \% \text {, glycerin } 20 \% \text {, flavoring } 4.5 \% \text {, }\end{array}$ \\
\hline Nocella (2018)[32] & $\begin{array}{l}\text { Electronic cigarettes: } \\
\text { tobacco-flavored E- } \\
\text { cigarette: }\end{array}$ & $\begin{array}{l}\text { The tobacco-flavored E-cigarette consists of a cartridge containing } 16 \mathrm{mg} \text { of nicotine and can produce the } \\
\text { equivalent of } 250 \text { puffs (additive not specified) }\end{array}$ \\
\hline Glantz (2018)[15] & IQOS (menthol) & $\mathrm{IQOS}^{\mathrm{TM}}$ is produced by Philip Morris International (PMI). Heat generated up to $350^{\circ} \mathrm{C}\left(660^{\circ} \mathrm{F}\right)$. \\
\hline Kerr (2019)[21] & electronic cigarette & $\begin{array}{l}\text { Each container can hold } 1.5 \mathrm{ml} \text { of e-liquid. Based on the information from the manufacturer, every } 10 \mathrm{ml} \text { of liquid } \\
\text { contains } 360-\mathrm{mg} \text { of nicotine, } 12.6 \mathrm{ml} \text { of propylene glycol, } 6.2 \mathrm{ml} \text { of vegetable glycerine, } 120 \mathrm{mg} \text { of vanillin, } 48 \mathrm{mg} \\
\text { of furaneol and } 80 \mathrm{mg} \text { of ethyl vanillin. }\end{array}$ \\
\hline $\begin{array}{l}\text { Biondi-Zoccai } \\
\text { (2019)[10] }\end{array}$ & $\begin{array}{l}\text { heat-not-burn } \\
\text { cigarettes (HNBC), } \\
\text { electronic vaping } \\
\text { cigarettes (EVC) }\end{array}$ & $\begin{array}{l}\text { - It is an electronic cigarette device consisting of a battery and liquid in a container containing glycerol, } \\
\text { propylene glycol, flavors, and nicotine } 1.6-19 \mathrm{mg} / \text { cartridge. Generate aerosol from heating process instead of } \\
\text { combustion. } \\
\text { - Heat-not-burn cigarette (HNBC) consists of heating components and tobacco sticks. Inhaled aerosols are } \\
\text { produced by up to } 350^{\circ} \mathrm{C} \text { of heating (without the combustion process). In contrast to EVS, HNBC does not } \\
\text { evaporate liquid components containing flavorings, propylene glycol, and vegetable glycerol. }\end{array}$ \\
\hline $\begin{array}{l}\text { Lorkiewicz } \\
(2019)[22]\end{array}$ & $\begin{array}{l}\text { Grizzly Premium } \\
\text { Straight ST, NJOY } \\
\text { King e-cigarette, } \\
\text { NJOY King Menthol }\end{array}$ & $\begin{array}{l}\text { Grizzly Premium Straight ST }(\sim 10.5 \mathrm{mg} / \mathrm{g} \text { nicotine }) \\
\text { NJOY King e-cigarette (2.4\% nicotine) } \\
\text { NJOY King Menthol (3.0\% nicotine) e-cigarette }\end{array}$ \\
\hline Gale (2020)[14] & glo THS & $\begin{array}{l}\text { Made of tobacco formed into stick shape. The heating chamber will heat the tobacco and releasing volatile } \\
\text { nicotine, glycerol and tobacco flavorings. The heat is resulted form heating chamber is is much lower than the } \\
\text { temperature of a cigarette (usually between } 350 \text { and } 900{ }^{\circ} \mathrm{C} \text { ). }\end{array}$ \\
\hline $\begin{array}{l}\text { Bosilkovska } \\
(2020)[11]\end{array}$ & $\begin{array}{l}\text { Carbon-Heated } \\
\text { Tobacco Products } \\
\text { (CHTP) }\end{array}$ & $\begin{array}{l}\text { CHTP uses a fast-lighting carbon heat source to heat a tobacco plug, embedded in the specially designed stick, to } \\
\text { produce aerosols that contain nicotine and tobacco flavor. CHTP investigational product tested in this research is } \\
\text { a non-menthol tobacco stick }(1.16 \mathrm{mg} \text { and } 0.45 \mathrm{mg} \text { of nicotine/stick. }\end{array}$ \\
\hline
\end{tabular}

\section{ACKNOWLEDGMENT}

This Systematic Review literature is supported by PT. Kharisma Persona Komunika.

\section{REFERENCES}

1. Popova L, Ling PM. Alternative Tobacco Product Use and Smoking Cessation: A National Study. Am J Public Health 2013; 103: 923-30.

2. Tucker JS, Shadel WG, Golinelli D, Ewing B. Alternative Tobacco Product Use and Smoking Cessation Among Homeless Youth in Los Angeles County. Nicotine Tob Res 2014; 16: 1522-6.

3. Jiang N, Ho SY, Wang MP, Leung LJ, Lam TH. Exclusive and concurrent use of cigarettes and alternative tobacco products among Hong Kong adolescents. Tob Prev Cessation 2018; 4:19.

4. Pisinger C, Døssing M. A systematic review of health effects of electronic cigarettes. Prev Med 2014; 69: 24860.
5. Farsalinos KE, Polosa R. Safety evaluation and risk assessment of electronic cigarettes as tobacco cigarette substitutes: a systematic review. Ther Adv Drug Saf 2014; 5: 67-86.

6. Gatechew B, Payne JB, Vu M, Pillai D, Shah J, Levine $\mathrm{H}$, et al. Perceptions of Alternative Tobacco Products, Anti-tobacco Media, and Tobacco Regulation among Young Adults: A Qualitative Study. Am J Health Behav 2018; 42: 118-30.

7. Centers for Disease Control and Prevention (US); National Center for Chronic Disease Prevention and Health Promotion (US); Office on Smoking and Health (US). How Tobacco Smoke Causes Disease: The Biology and Behavioral Basis for Smoking-Attributable Disease: A Report of the Surgeon General. https://www.ncbi.nlm.nih.gov/books/NBK53014/ (Accessed Feb 19, 2021).

8. Rowley J, Slack F. Conducting a literature review. Manag Res News 2004; 27: 31-9.

9. Adriaens, K, Gucht, DV, Baeyens F. IQOS ${ }^{\mathrm{TM}}$ vs. ecigarette vs. tobacco cigarette: A direct comparison of 
International Journal of Pharma Research and Health Sciences, 2021; 9 (1): 3270-3279

short-term effects after overnight-abstinence. Int $\mathbf{J}$

Environ Res Public Health 2018; 15(12).

10. Biondi-Zoccai G, Sciarretta S, Bullen C, Nocella C, Violi F, Loffredo L, et al. Acute Effects of Heat-NotBurn, Electronic Vaping, and Traditional Tobacco Combustion Cigarettes: The Sapienza University of Rome-Vascular Assessment of Proatherosclerotic Effects of Smoking (SUR-VAPES) 2 Randomized Trial. J Am Heart Assoc 2019; 8: e010455.

11. Bosilkovska, M. Exposure to harmful and potentially harmful constituents decreased in smokers switching to Carbon-Heated Tobacco Product. Toxicol Lett 2020; 330: 30-40.

12. Brossard P, Weitkunat R, Poux V, Lama N, Haziza C, Picavet $\mathrm{P}$, et al. Nicotine pharmacokinetic profiles of the Tobacco Heating System 2.2, cigarettes and nicotine gum in Japanese smokers. Regul Toxicol Pharmacol 2017; 193-9.

13. D'Ruiz CD, Graff DW, Robinson E. Reductions in biomarkers of exposure, impacts on smoking urge and assessment of product use and tolerability in adult smokers following partial or complete substitution of cigarettes with electronic cigarettes. BMC Public Health 2016; 16: 453-64.

14. Gale N, McEwan M, Camacho OM, Hardie G, Murphy J, Proctor CJ. Changes in Biomarkers of Exposure on Switching From a Cigarette to the glo Tobacco Heating Product: A Randomized, Controlled Ambulatory Study. Nicotine Tob Res 2020; 1-8.

15. Gale N, McEwan M, Eldridge AC, Sherwood N, Bowen $\mathrm{E}, \mathrm{McDermott} \mathrm{S}$, et al. A randomised, controlled, twoCentre open-label study in healthy Japanese subjects to evaluate the effect on biomarkers of exposure of switching from a cigarette to a tobacco heating product. BMC Public Health 2017; 17: 1-18.

16. Glantz SA. PMI's own in vivo clinical data on biomarkers of potential harm in Americans show that IQOS is not detectably different from cigarettes. Tob Control 2018;27: s9-s12.

17. Göney G, Çok , Tamer U, Burgaz S, Şengezer T. Urinary cotinine levels of electronic cigarette (ecigarette) users. Toxicol Mech Methods 2016; 26: 4148.

18. Haziza C, de La Bourdonnaye G, Skiada D, Ancerewicz J, Baker G, Picavet P, et al. Evaluation of the Tobacco Heating System 2.2. Part 8: 5-Day randomized reduced exposure clinical study in Poland. Regul Toxicol Pharmacol 2016; 81: S139-50.

19. Hecht SS, Carmella SG, Kotandeniya D, Pillsbury ME, Chen M, Ransom BWS, et al. Evaluation of toxicant and carcinogen metabolites in the urine of e-cigarette users versus cigarette smokers. Nicotine Tob Res 2015; 17: 704-9.

20. Ikonomidis I, Vlastos D, Kourea K, Kostelli G, Varoudi M, Pavlidis G, et al. Electronic cigarette smoking increases arterial stiffness and oxidative stress to a lesser extent than a single cigarette. Circulation 2018; 137: 303-6.

21. Kerr DMI, Brooksbank KJM, Taylor RG, Pinel K, Rios FJ, Touyz RM, et al. Acute effects of electronic and tobacco cigarettes on vascular and respiratory function in healthy volunteers: A cross-over study. J Hypertens 2019; 37: 154-66.

22. Lorkiewicz P, Riggs DW, Keith RJ, Conklin DJ, Xie Z, Sutaria S, et al. Comparison of Urinary Biomarkers of Exposure in Humans Using Electronic Cigarettes, Combustible Cigarettes, and Smokeless Tobacco. Nicotine Tob Res 2019; 21:1228-38.

23. Lüdicke F, Baker G, Magnette J, Picavet P, Weitkunat R. Reduced exposure to harmful and potentially harmful smoke constituents with the Tobacco Heating System 2.1. Nicotine Tob Res 2017; 19: 168-75.

24. Lüdicke F, Haziza C, Weitkunat R, Magnette J. Evaluation of biomarkers of exposure in smokers switching to a carbon-heated tobacco product: A controlled, randomized, open-label 5-day exposure study. Nicotine Tob Res 2016; 18: 1606-13.

25. Ludicke F, Michael Ansari S, Lama N, Blanc N, Bosilkovska M, Donelli A, et al. Effects of switching to a heat-not-burn tobacco product on biologically relevant biomarkers to assess a candidate modified risk tobacco product: A randomized trial. Cancer Epidemiol Biomarkers Prev 2019; 28: 1934-43.

26. Lüdicke F, Picavet P, Baker G, Haziza C, Poux V, Lama $\mathrm{N}$, et al. Effects of switching to the menthol tobacco heating system 2.2, smoking abstinence, or continued cigarette smoking on clinically relevant risk markers: A randomized, controlled, open-label, multicenter study in sequential confinement and ambulatory settings (Part 2). Nicotine Tob Res 2018; 20: 173-82.

27. Manzoli L, Flacco ME, Ferrante M, La Vecchia C. Siliquini, R, Ricciardi, W, et al. Cohort study of electronic cigarette use: Effectiveness and safety at 24 months. Tob Control 2017; 26: 284-92.

28. Manzoli L, Flacco ME, FioreM, La Vecchia C, Marzuillo C, Gualano MR, et al. Electronic cigarettes efficacy and safety at 12 months: Cohort study. PLoS ONE 2015; 10: 1-14.

29. McConnell R, Barrington-Trimis JL, Wang K, Urman $\mathrm{R}$, Hong $\mathrm{H}$, Unger $\mathrm{J}$, et al. Electronic cigarette use and respiratory symptoms in adolescents. Am J Respir Crit Care Med 2017; 195:1043-9.

30. Meier E, Wahlquist AE, Heckman BW, Cummings KM, Froeliger B, Carpenter MJ. A pilot randomized crossover trial of electronic cigarette sampling among smokers. Nicotine Tob Res 2017; 19: 176-82.

31. Miura N, Yuki D, Minami N, Kakehi A, Futamura Y. A study to investigate changes in the levels of biomarkers of exposure to selected cigarette smoke constituents in Japanese adult male smokers who switched to a non- 
International Journal of Pharma Research and Health Sciences, 2021; 9 (1): 3270-3279

combustion inhaler type of tobacco product. Regul Toxicol Pharmacol 2015; 71: 498-506.

32. Nocella C, Biondi-Zoccai G, Sciarretta S, Peruzzi M, Pagano F, Loffredo L, et al. Impact of Tobacco Versus Electronic Cigarette Smoking on Platelet Function. Am J Cardiol 2018; 122: 1477-81.

33. Pasquereau A, Guignard R, Andler R, Nguyen-Thanh, $\mathrm{V}$. Electronic cigarettes, quit attempts and smoking cessation: a 6-month follow-up. Addiction 2017; 112: 1620-8.

34. Rigotti NA, Chang Y, Tindle HA, Kalkhoran SM, Levy DE, Regan S, et al. Association of E-cigarette use with smoking cessation among smokers who plan to quit after a hospitalization a prospective study. Ann Intern Med 2018; 168: 613-20.

35. Stein MD, Caviness C, Grimone K, Audet D, Anderson BJ, Bailey GL. An open trial of electronic cigarettes for smoking cessation among methadone-maintained smokers. Nicotine Tob Res 2016; 18: 1157-62.

36. Yan XS, D'Ruiz C. Effects of using electronic cigarettes on nicotine delivery and cardiovascular function in comparison with regular cigarettes. Regul Toxicol Pharmacol 2015; 71: 24-34.

37. O'Connell G, Graff DW, D'Ruiz CD. Reductions in biomarkers of exposure (BoE) to harmful or potentially harmful constituents (HPHCs) following partial or complete substitution of cigarettes with electronic cigarettes in adult smokers. Toxicol Mech Methods 2016; 26: 453-64.

38. Adriaens K, Gucht DV, Baeyens F. IQOSTM vs. eCigarette vs. Tobacco Cigarette: A Direct Comparison of Short-Term Effects after Overnight-Abstinence. International Journal of Environtmental Research and Public Health 2018;15: 2902.

39. Hatsukami DK, Meier E, Lindgren BR, Anderson A, Reisinger SA, Norton KJ, et al. A randomized clinical trial examining the effects of instructions for electronic cigarette use on smoking-related behaviors and biomarkers of exposure. Nicotine Tob Res 2020; 22: 1524-32.

CONFLICT OF INTEREST: The authors declare no conflict of interest, financial or otherwise.

SOURCE OF FUNDING: None.

AVAILABILITY OF DATA AND MATERIALS: Not applicable.

CONSENT FOR PUBLICATION: Not applicable.

ETHICS APPROVAL AND CONSENT TO

PARTICIPATE: Not applicable.
HUMAN AND ANIMAL RIGHTS: No animals/humans were used for this study. 